\title{
Metaheuristic Optimization of Fractional Order Incremental Conductance (FO-INC) Maximum Power Point Tracking (MPPT)
}

\author{
Hossam Hassan Ammar, ${ }^{1,2}$ Ahmad Taher Azar (D), ${ }^{3,4}$ Raafat Shalaby (D), \\ and M. I. Mahmoud ${ }^{5}$ \\ ${ }^{1}$ School of Engineering and Applied Science, Nile University, Giza, Egypt \\ ${ }^{2}$ Smart Engineering Systems Research Center (SESC), Nile University, 12588 Shaikh Zayed City, Giza, Egypt \\ ${ }^{3}$ Robotics and Internet-of-Things Lab (RIOTU), Prince Sultan University, Riyadh 12435, Saudi Arabia \\ ${ }^{4}$ Faculty of Computers and Artificial Intelligence, Benha University, Banha, Egypt \\ ${ }^{5}$ Faculty of Electronic Engineering, Menofia University, Menofia, Egypt \\ Correspondence should be addressed to Ahmad Taher Azar; ahmad_t_azar@ieee.org
}

Received 25 July 2019; Revised 7 October 2019; Accepted 18 October 2019; Published 28 November 2019

Guest Editor: Jianwu Zeng

Copyright (C) 2019 Hossam Hassan Ammar et al. This is an open access article distributed under the Creative Commons Attribution License, which permits unrestricted use, distribution, and reproduction in any medium, provided the original work is properly cited.

\begin{abstract}
This paper seeks to improve the photovoltaic (PV) system efficiency using metaheuristic, optimized fractional order incremental conductance (FO-INC) control. The proposed FO-INC controls the output voltage of the PV arrays to obtain maximum power point tracking (MPPT). Due to its simplicity and efficiency, the incremental conductance MPPT (INC-MPPT) is one of the most popular algorithms used in the PV scheme. However, owing to the nonlinearity and fractional order (FO) nature of both PV and DC-DC converters, the conventional INC algorithm provides a trade-off between monitoring velocity and tracking precision. Fractional calculus is used to provide an enhanced dynamical model of the PV system to describe nonlinear characteristics. Moreover, three metaheuristic optimization techniques are applied; Particle Swarm Optimization (PSO), Ant Colony Optimization (ACO), and AntLion Optimizer (ALO) are used for tuning the FO parameters of the proposed INC-MPPT. A MATLAB-Simulink-based model of the PV and optimization have been developed and simulated for different INC-MPPT techniques. Different techniques aim to control the boost DCDC converter towards the MPP. The proposed optimization algorithms are, also, developed and implemented in MATLAB to tune the target parameters. Four performance indices are also introduced in this research to show the reliability of the comparative analysis of the proposed FO-INC with metaheuristic optimization and the conventional INC-MPPT algorithms when applied to a dynamical PV system under rapidly changing weather conditions. The simulation results show the effective performance of the proposed metaheuristic optimized FO-INC as a MPPT control for different climatic conditions with disturbance rejection and robustness analysis.
\end{abstract}

\section{Introduction}

Green energy sources are the primary research goal nowadays as they are viable, ecological, and cost-effective energy sources. Solar, wind, tidal, and biomass energy have penetrated the electric power production market in recent years due to the diverse methods and their renewable nature. The benefits of developing renewable power include reducing fossil fuel usage, mitigating the greenhouse impact, and reducing air pollution [1]. In addition, control approaches and optimization have shown that the performance of photovoltaic devices depends upon climate conditions (sunlight and temperature) and load impedance [2]. However, its low energy conversion effectiveness (especially in low radiation and temperatures) is the primary disadvantage of PV systems. The MPPT needs to be operated for ideal efficiency and operation as mentioned [3]. One of the pioneering challenges of the PV devices is their nonlinear current-voltage I-V relationship dynamic which generates a distinctive MPP in the power-voltage $\mathrm{P}-\mathrm{V}$ relationship as noted [4]. Because of the P-V relationship with climate and load circumstances, the MPPT method becomes complex. MPPT methods do not only enhance the power performance of $\mathrm{PV}$ and energy 
delivered to the load, but they also increase the operating life of the PV system [5]. Previous studies have suggested several MPPT methods; most MPPT techniques demonstrate higher efficiency under stable weather [6]. MPPT algorithms are usually used as electronic power conversion devices and the control signal is a duty cycle for peak load energy [7]. A wide variety of methods for solving the MPPT issue have been implemented, such as the perturb and observe ( $\mathrm{P} \& \mathrm{O})$ method, incremental conductance (INC) algorithm, and artificial intelligence includes fuzzy logic, neural networks, and metaheuristic techniques. The $\mathrm{P} \& \mathrm{O}$ and INC are the most common algorithms used for PVMPPT systems [8]. The $\mathrm{P} \& \mathrm{O}$ technique is frugal and very easy to execute; its operation is based on the iterative measurement of the voltage and current of the PV system to obtain the duty cycle and consequently the MPP. Its main disadvantage, however, is that it provides an oscillatory power around the MPP and is also unable to manipulate PV power variations due to climatic effects or inherent disturbances of the MPPT. The INC approach is based on the behavior of PV, given that a MPP is reached by zero in a pitch of the PV curve, positive to the left and negative to the right of the PV curve. On the basis of this, the technique calculates the DC-DC converter duty cycle by relating iterative conductivity to the incremental conductivity. The primary drawback in the INC technique is that the system's reaction to the MPP may be slow under some conditions. However, the INC technique exhibits less oscillatory behavior around the MPP compared to the P\&O method [9]. Fractional calculus introduces the nonintegral order/ fractional of derivatives and integrals. Many of the real systems show a nonlinear and fractional order dynamical behavior, such as heat conduction in solids, electrical behavior in R-L transportation lines, mass diffusion, and electromagnetic waves [10]. The nonlinear characteristics of the current-voltage of a PV cell occur because the PV cells are manufactured from semiconducting materials (crystalline silicon, c-Si). The power of PV cell depends on the inherent voltage drop across the p-n junction (energy band) which produces a photoelectric current (current source). The light and ambient temperature interaction also shows anomalous diffusion which can be described as fractional order diffusion [11]. Therefore, GrunwaldLetnikov fractional approximation [12] is introduced to control the fractional order differentiation for current and voltage nonlinear dynamical behavior. To improve dynamic performance, FO-INC based on the nonlinear and fractional order changes of the PV voltage and current has been proposed to track the maximum output power [13]. It is very important to select the proper converter [14] to enhance the MPPT performance. The MPPT techniques have been compared using MATLAB and Simulink tools created by MathWorks, considering all the design and implementation specs [15]. Therefore, metaheuristic optimization techniques' robustness and ability to find the optimal solution in different nonlinear systems have demonstrated itself in numerous past research studies. Metaheuristic abilities are powerful techniques of resolving optimization problems for nonlinear and fractional order systems [15]. In power systems, different optimization techniques have been utilized. Considering the different constraints in PV systems and difference in the nature of DC-DC converter system, the ACO algorithm has been used [16]. It has been proved to be very robust, consistent, and performs better than conventional optimization techniques (e.g., PSO and GA) [16]. The experiments show computational effectiveness and time decrease in monitoring for a small PV Systems. The AntLion optimizer (ALO) is a recent metaheuristic algorithm that replicates the hunting scheme of antlions in catching ants [17]. ALO also gives a good performance results in PV-MPPT systems [18].This research aims to extract maximum power from PV systems by using FO-INC and metaheuristic optimization technique. This enhanced system efficiency in different climatic conditions using fixed and variable-step FOINC with PSO, ACO, and ALO optimization techniques. This paper is organized as follows: Section 2 addresses the modeling of the complete PV system, and Section 3 describes the MPPT algorithm design and operation. Section 4 gives the operation of metaheuristic optimization algorithms. Sections 5 and 6 illustrate the experimental results and conclusions to show the efficiency of the proposed technique.

\section{Photovoltaic (PV) System Modeling and Simulation}

The proposed PV system is constituted by a PV module, the Buck-Boost converter as a DC-DC converter between the PV panel and the DC load, and the MPPT controller to achieve maximum power point of the PV panels. The model of the solar panels used in the proposed system will be illustrated, and the PV system is introduced [19]. The inputs to MPPT are the PV voltage and current which are used to calculate and deliver the control signal (duty cycle) to the Buck-Boost converter, as shown in Figure 1. The main function of the MPPT algorithm is to automatically track the voltage/current change of the PV panel and feed the Buck-Boost converter with the appropriate duty cycle to get the MPP under specific climatic conditions.

2.1. Modeling of PV Panel. The nonlinear equations of the PV system which describe the relationships between the different PV model parameters are developed and solved via MATLAB and Simulink tools where the PV cell electric circuit model is shown in Figure 2. The PV output current $I_{\mathrm{PV}}$ can be obtained using equation (1) where $N_{\mathrm{p}}$ and $N_{\mathrm{s}}$ are the number of parallel and series cells, respectively:

$$
I_{\mathrm{PV}}=N_{\mathrm{p}} \times\left(I_{\mathrm{G}}-I_{\mathrm{D}}-I_{\mathrm{sh}}\right) .
$$

The nonlinear equation of I-V characteristics of onediode PV model was expressed by Milici et al. [9] as follows:

$$
\begin{aligned}
I_{\mathrm{PV}}= & N_{\mathrm{p}} \times I_{\mathrm{G}}-N_{\mathrm{s}} \times I_{\mathrm{o}}\left[e^{\left.\left(\left(q / \eta k T_{k}\right) \times\left(\left(V_{\mathrm{PV}} / N_{\mathrm{s}}\right)+\left(I_{\mathrm{PV}} / N_{\mathrm{p}}\right) R_{\mathrm{s}}\right)-1\right)\right]}\right. \\
& -\frac{N_{\mathrm{p}}}{R_{\mathrm{sh}}} \times\left(\frac{V_{\mathrm{PV}}}{N_{\mathrm{s}}}+\frac{I_{\mathrm{PV}} R_{\mathrm{s}}}{N_{\mathrm{p}}}\right),
\end{aligned}
$$




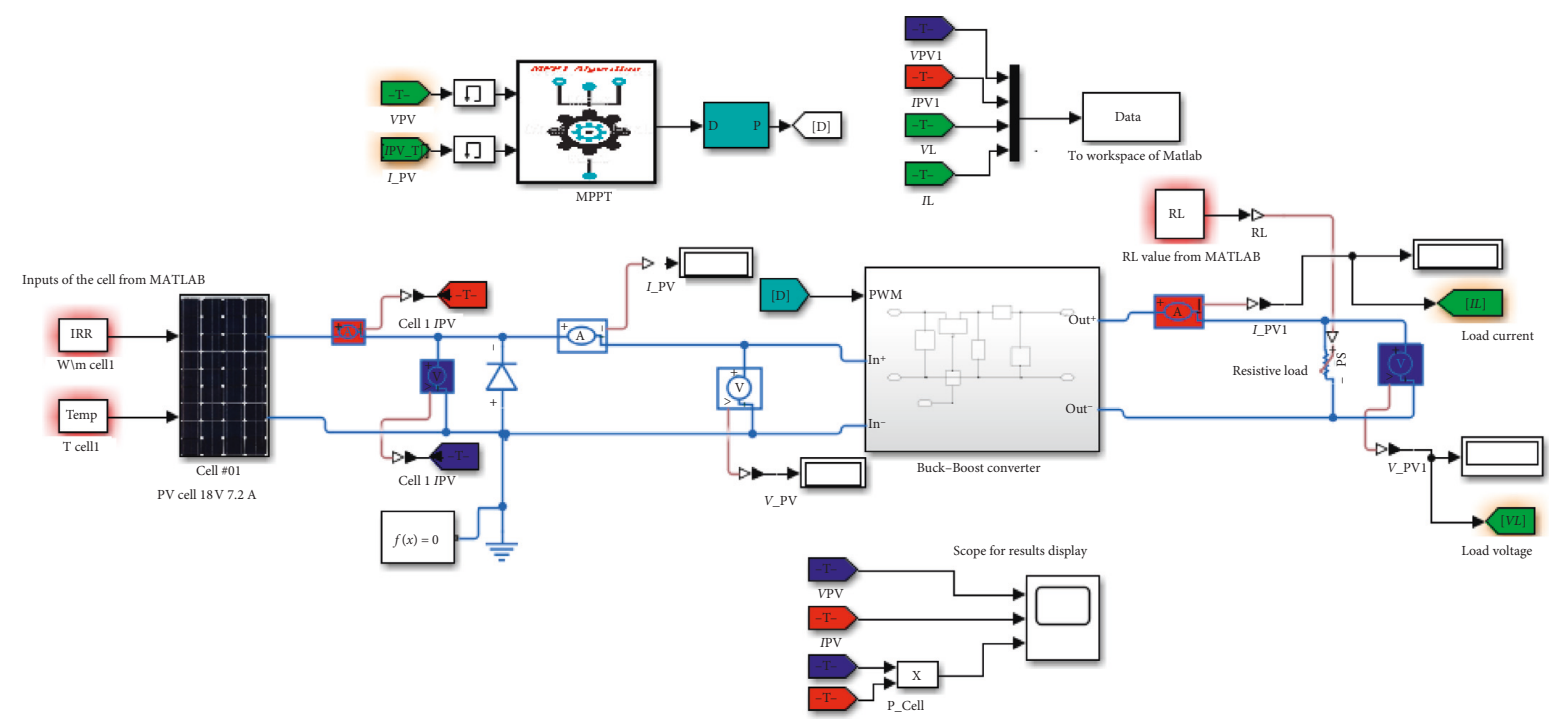

FIgure 1: Complete PV system model using MATLAB and Simscape.

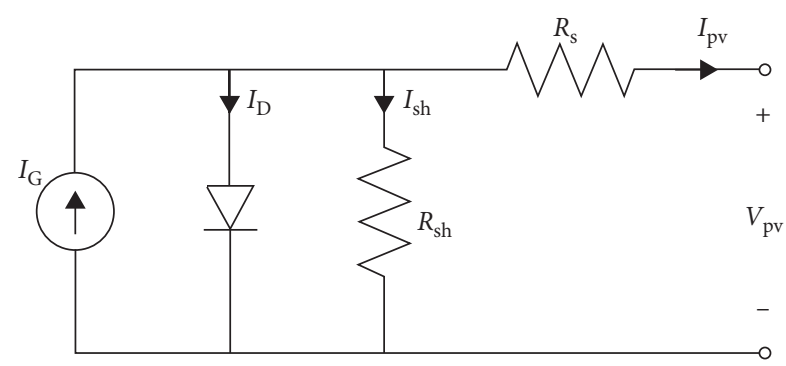

Figure 2: PV cell equivalent electric circuit model.

where $V_{\mathrm{PV}}$ and $I_{\mathrm{PV}}$ are the PV terminal voltage and current, respectively, $R_{\mathrm{s}}$ and $R_{\mathrm{sh}}$ are the series and shunt resistance, respectively, $\eta$ is the ideality factor, the Boltzmann's constant is $k, q$ is the electron charge, $T_{k}$ is the temperature degree in Kelvin, $I_{\mathrm{G}}$ is photo-generated current, and the diode saturation current is $I_{0}$. The PV panel parameters are shown in Table 1.

The I-V and P-V nonlinear characteristic curves of the PV array simulated using MATLAB at different climatic conditions (temperature and irradiance) are shown in Figure 3.

2.2. DC-DC Converter. Simulink and Simscape tools have been selected as platforms for modeling, implementation, and testing the Buck-Boost converter. The state space modeling is primarily represented by equation (3), where $A, B, C$, and $D$ are the system matrices, $x$ is the state variable vector, $x^{\prime}$ is the state variable derivative vector with respect to time, $u$ is the input, and $y$ is the output [14]:

$$
\begin{array}{r}
x^{\prime}=A x+B u, \\
y=C x+D u .
\end{array}
$$

Figure 4 shows the Buck-Boost model using Simscape which is simulated at different duty cycles and fixed load
TABLE 1: PV panel parameters.

\begin{tabular}{lc}
\hline Parameter value & Value \\
\hline Max power $P_{\max }$ & $735.72 \mathrm{~W}$ \\
Open circuit voltage $V_{\text {oc }}$ & $65.9 \mathrm{~V}$ \\
Short circuit current $I_{\text {sh }}$ & $15.21 \mathrm{~A}$ \\
Temperature coefficient of $V_{\mathrm{OC}}$ & $-1.23 \times 10 e^{-1} \mathrm{~V} / \mathrm{C}$ \\
Temperature coefficient of $I_{\mathrm{sh}}$ & $3.18 \times 10 e^{-3} \mathrm{~A} / \mathrm{C}$ \\
\hline
\end{tabular}

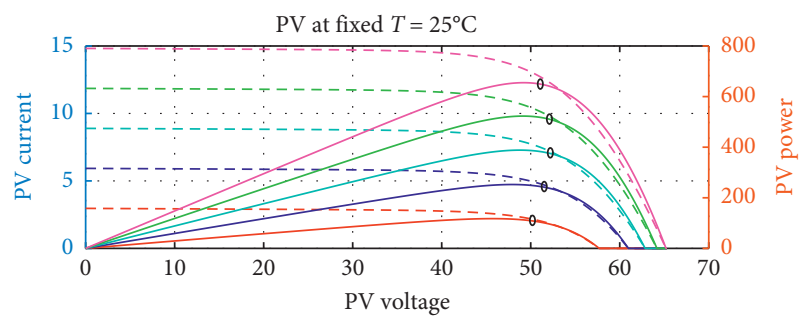

$$
\begin{array}{ll}
---200 \mathrm{~W} \backslash \mathrm{m}^{2} & --800 \mathrm{~W} \backslash \mathrm{m}^{2} \\
---400 \mathrm{~W} \backslash \mathrm{m}^{2} & ---1000 \mathrm{~W} \backslash \mathrm{m}^{2} \\
---600 \mathrm{~W} \backslash \mathrm{m}^{2} &
\end{array}
$$

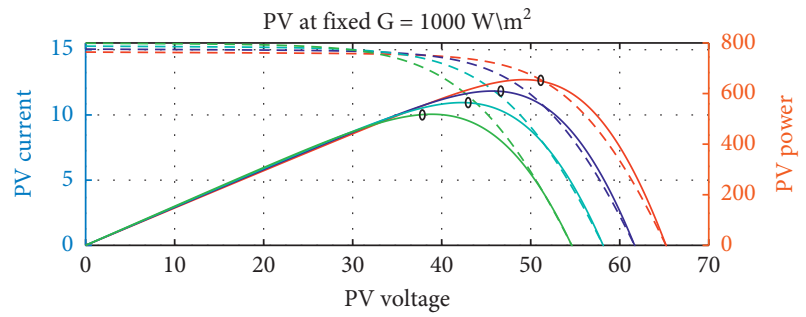

$--25^{\circ} \mathrm{C} \quad--55^{\circ} \mathrm{C}$

FIgURE 3: P-V and I-V characteristic curves at different climatic conditions.

according to the state space model represented in equation (4), where $x_{1}=I_{\mathrm{L}}, x_{2}=V_{C_{\text {out }}}$, and $d=$ duty cycle. The simulation results at different duty cycles are shown in Figure 5: 


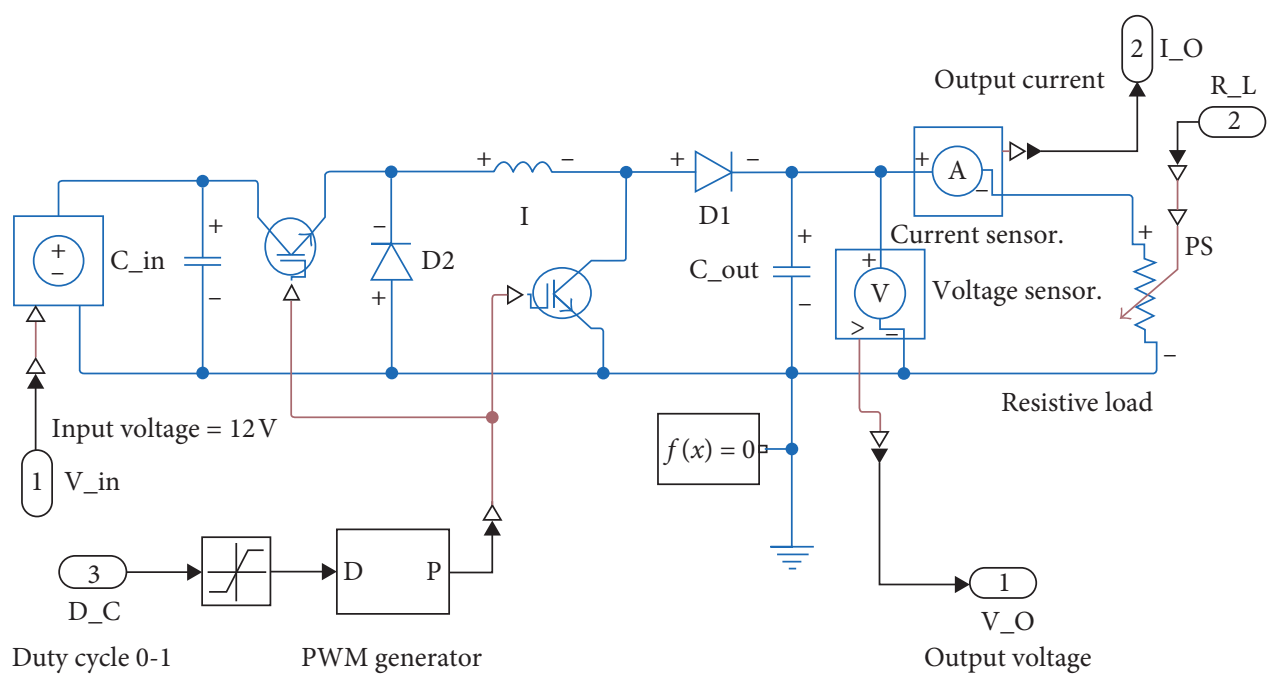

Figure 4: Buck-Boost Simscape model.

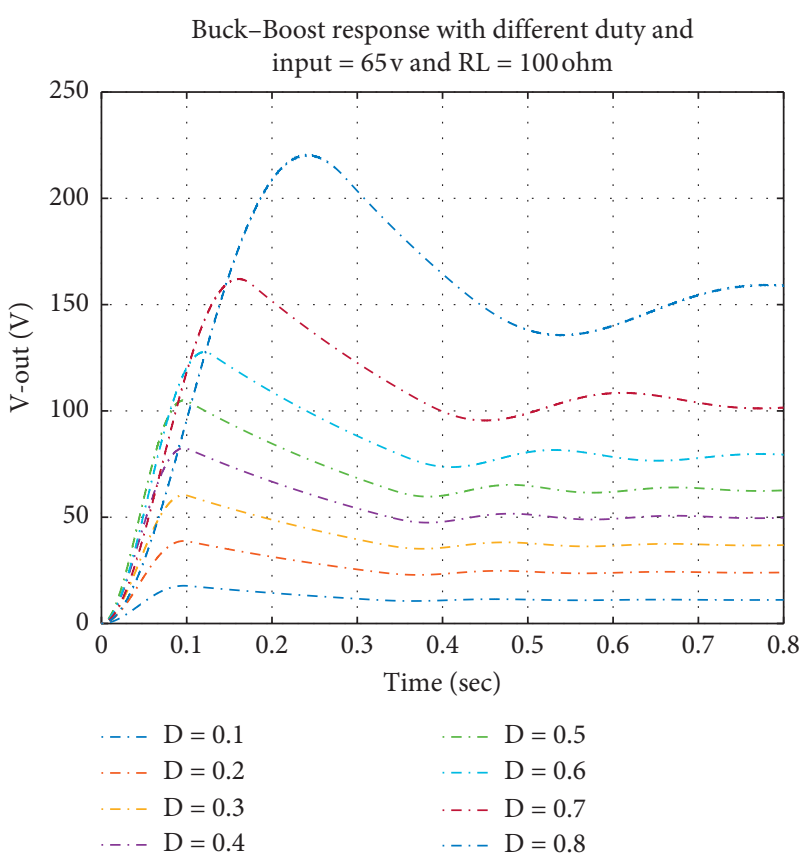

Figure 5: Buck-Boost output voltage at different duty cycles.

$$
\begin{aligned}
& {\left[\begin{array}{l}
x_{1}^{\prime} \\
x_{2}^{\prime}
\end{array}\right]=\left[\begin{array}{cc}
0 & \frac{1-d}{L} \\
\frac{-(1-d)}{C} & \frac{-1}{R C}
\end{array}\right]\left[\begin{array}{l}
x_{1} \\
x_{2}
\end{array}\right]+\left[\begin{array}{l}
\frac{d}{L} \\
0
\end{array}\right] u_{1},} \\
& {\left[\begin{array}{l}
y_{1} \\
y_{2}
\end{array}\right]=\left[\begin{array}{ll}
1 & 0 \\
0 & 1
\end{array}\right]\left[\begin{array}{c}
I_{L} \\
V_{C_{\text {out }}}
\end{array}\right]+\left[\begin{array}{l}
0 \\
0
\end{array}\right] u_{1} .}
\end{aligned}
$$

The proposed Buck-Boost has been designed and simulated using the parameters illustrated in Table 2.
TABLE 2: Buck-Boost design parameters.

\begin{tabular}{lc}
\hline Parameter value & Value \\
\hline Load resistance & $4.5 \Omega$ \\
Filter inductance & $1 \mathrm{mH}$ \\
Output filter capacitance & $4700 \mu \mathrm{F}$ \\
Input filter capacitance & $47 \mu \mathrm{F}$ \\
Switching frequency & $25000 \mathrm{~Hz}$ \\
\hline
\end{tabular}

\section{Design and Implementation of MPPT}

The primary feature of the PV system is the total energy monitoring in which the power of the PV modules can be extracted in a certain climatic situation. As shown in the literature, the most commonly used MPPT algorithm is INC. The INC algorithm is based on the reality that the PV output energy derivative for the output voltage at the MPP is zero $(\mathrm{d} P / \mathrm{d} V=0)$, positive on the left side of MPP $(\mathrm{d} P / \mathrm{d} V>0)$ and negative on the right side of MPP $(\mathrm{d} P / \mathrm{d} V<0)[5]$.

3.1. Fixed-step INC Method. The INC algorithm is used to detect the condition of MPP via the conductance $(\mathrm{d} I / \mathrm{d} V)$ behavior of the PV system. The INC-MPPT can be executed through the following sequence [20]:

(1) The voltage and current of the PV module are sensed by the MPPT controller

(2) If $(\mathrm{d} I / \mathrm{d} V<-I / V)$ is satisfied, the duty cycle of the converter needs to be decreased and vice versa

(3) No change in the duty cycle occurs if $I+V(\mathrm{~d} I / \mathrm{d} v)=$ 0 is satisfied

The duty cycle (PV reference voltage $\left.\left(V_{\text {ref }}\right)\right)$ increasing or decreasing occurs with fixed step.

3.2. Variable-Step INC Method. The INC variable step size algorithm proposed by Motahhir et al. [5] can improve the MPPT controller's tracking effectiveness. The algorithm 
sequences are mostly comparable to the standard increments; the only distinction is the calculation of the step size. Step $=N *$ abs $(\mathrm{d} P / \mathrm{d} V)$ is used in the variable step size algorithm to change the duty cycle step size, where $N$ is the scaling factor.

3.3. Fractional Order INC Method (FO-INC). Many computational requests for fractional order derivatives according to the definition have been suggested by Riemann-Liouville and Grunwald-Letnikov, [9]. The general form of fractional order differentiator can be expressed by Kamal and Ibrahim [21]; supposed that $f_{m}(t)=t^{m}$ and $m=1,2,3, \ldots$, is demonstrated at

$$
D_{\alpha}^{t} t^{m} \approx \frac{\Gamma(m+1)}{\Gamma((m+1)-\alpha)} t^{(m-\alpha)},
$$

where $\Gamma(\cdot)$ represents Eular's gamma function and $\alpha$ is the order number of derivative, when its value is $0<\alpha<1$, representing physical phenomenon of fractional order [9]. The FO-INC MPPT main criteria can be expressed by equations (7) and (8):

$$
\begin{aligned}
\frac{\mathrm{d}^{\alpha} I(V)}{\mathrm{d} V^{\alpha}} & =\lim _{\Delta V \longrightarrow 0} \frac{I(V)-\alpha(V-\Delta V)}{\Delta V \alpha}, \\
\frac{\mathrm{d}^{\alpha} I}{\mathrm{~d} V^{\alpha}} & \approx \frac{I-\alpha I_{0}}{\left(V-V_{0}\right)^{\alpha}}, \\
\frac{\mathrm{d}^{\alpha}}{\mathrm{d} V^{\alpha}}\left(\frac{-I_{0}}{V_{0}}\right) & =\left(\frac{-1}{V}\right)\left(\frac{\Gamma(2)}{\Gamma(2-\alpha)}\right)\left(I_{0}\right)^{1-\alpha}-I_{0} \frac{\Gamma(0)}{\Gamma(-\alpha)} V_{0}^{1-\alpha} .
\end{aligned}
$$

The control procedure of the FO-INC algorithm can be expressed by the flowchart depicted in Figure 6. The procedure starts with measuring the PV's voltage and current to determine the MPPT action according to the following conditions:

Condition 1. If $\left(\Delta V^{\alpha} \neq 0 \&\left(\mathrm{~d}^{\alpha} I / \mathrm{d} V^{\alpha}\right)=\left(\mathrm{d}^{\alpha} / \mathrm{d} V^{\alpha}\right)\right.$ $\left.\left(-I_{0} / V_{0}\right)\right)$ or $\left(\Delta V^{\alpha}=0 \& \Delta I=0\right)$, keep the current duty cycle, fix the duty cycle

Condition 2. If $\left(\Delta V^{\alpha} \neq 0 \&\left(\mathrm{~d}^{\alpha} I / \mathrm{d} V^{\alpha}\right)>\left(\mathrm{d}^{\alpha} / \mathrm{d} V^{\alpha}\right)\right.$ $\left.\left(-I_{0} / V_{0}\right)\right)$ or $\left(\Delta V^{\alpha}=0 \& \Delta I>0\right)$, decrease the duty cycle of the Buck-Boost converter (increase $V_{\text {ref }}$ as in equation (9))

Condition 3. If $\left(\Delta V^{\alpha} \neq 0 \&\left(\mathrm{~d}^{\alpha} I / \mathrm{d} V^{\alpha}\right)<\left(\mathrm{d}^{\alpha} / \mathrm{d} V^{\alpha}\right)\right.$ $\left.\left(-I_{0} / V_{0}\right)\right)$ or $\left(\Delta V^{\alpha}=0 \& \Delta I<0\right)$, increase the duty cycle of the Buck-Boost converter (decrease $V_{\text {ref }}$ as in equation (9))

Condition 4. Calculate $P_{\mathrm{o}}=V_{\mathrm{o}} \times I_{\mathrm{o}}$ and $P=V \times I$. If $P>P_{\mathrm{o}} \longrightarrow$ terminate, otherwise update the voltage $V_{\mathrm{o}}=V$, current $I_{\mathrm{o}}=I$, and power $P_{\mathrm{o}}=P$

The duty cycle of the Buck-Boost converter can be calculated based on the output of the FO-INC controller $V_{\text {ref }}$ as in

$$
\begin{gathered}
V_{\mathrm{L}}=\frac{D}{1-D} \times V_{\mathrm{PV}} \text { then, } \\
D=\frac{V_{\mathrm{L}}}{\left(V_{0} \pm \Delta V^{\alpha}\right)+V_{\mathrm{L}}},
\end{gathered}
$$

where $V_{\mathrm{L}}$ is the resistive load voltage, $V_{\mathrm{PV}}=V_{\text {ref }}$, and $D$ is the duty cycle.

Both fixed- and variable-step FO-INC MPPT have been implemented to improve the performance of the MPP tracking of the nonlinear PV system with Buck-Boost converter and resistive load. In case of fixed step, the effective parameter of MPPT performance is alpha $\alpha$. For variable step both alpha $(\alpha)$ and step size $S$ are affecting the MPPT performance as shown in Figure 6.

\section{Metaheuristic Optimization Algorithms}

Genetic algorithms, Particle Swarm Optimization, and Ant Colony Optimization are among the most frequent algorithms in this field. However, these algorithms can solve many real and difficult problems. As one of the recent algorithms, the AntLion Optimizer Optimizer will be introduced along with its basic working principle, updated criteria, and pseudo algorithms. According to Pradhan et al. [20], the searching techniques of different optimizers are as follows:

(1) Initialize solution randomly

(2) Specify the search direction

(3) Specify the update criteria

(4) Specify the stopping criteria

4.1. Particle Swarm Optimization (PSO). The inspiration of the particle swarm algorithm is to simulate the navigation and foraging of swarm of birds or school of fishes. PSO was developed by James Kennedy and Russel Eberhart in 1995 while studying the social behaviors of animals working in swarms [22]. The PSO is seeking high-quality optimization by refining, iteratively, a candidate solution. The pseudo code of the PSO algorithm is illustrated in detail with the steps in Algorithm 1.In Algorithm 1, N is the number of particles, $C_{1}$ and $C_{2}$ are the acceleration coefficients, and $W_{\min }$ and $W_{\max }$ are the ranges of weight of particles. PSO uses fewer resources than the other optimization techniques. Usually, it does not require the problem to be differentiable as the gradient of the problem is not taken into consideration. As a result, there might be chances that PSO does not converge to optimal solution.

4.2. Ant Colony Optimization (ACO). Ant Colony Optimization (ACO) introduces an artificial algorithm motivating actual ant colonies that solve discrete optimization problem. It was first presented by Marco Dorigo in 1992 as a major aspect of his Ph.D thesis and called it the ant system [12]. While further improvements were carried out to ant colony by Gambardella Dorigo in 1997 [23]. Pseudo code for ant colony optimization is implemented with the steps as Algorithm 2. 


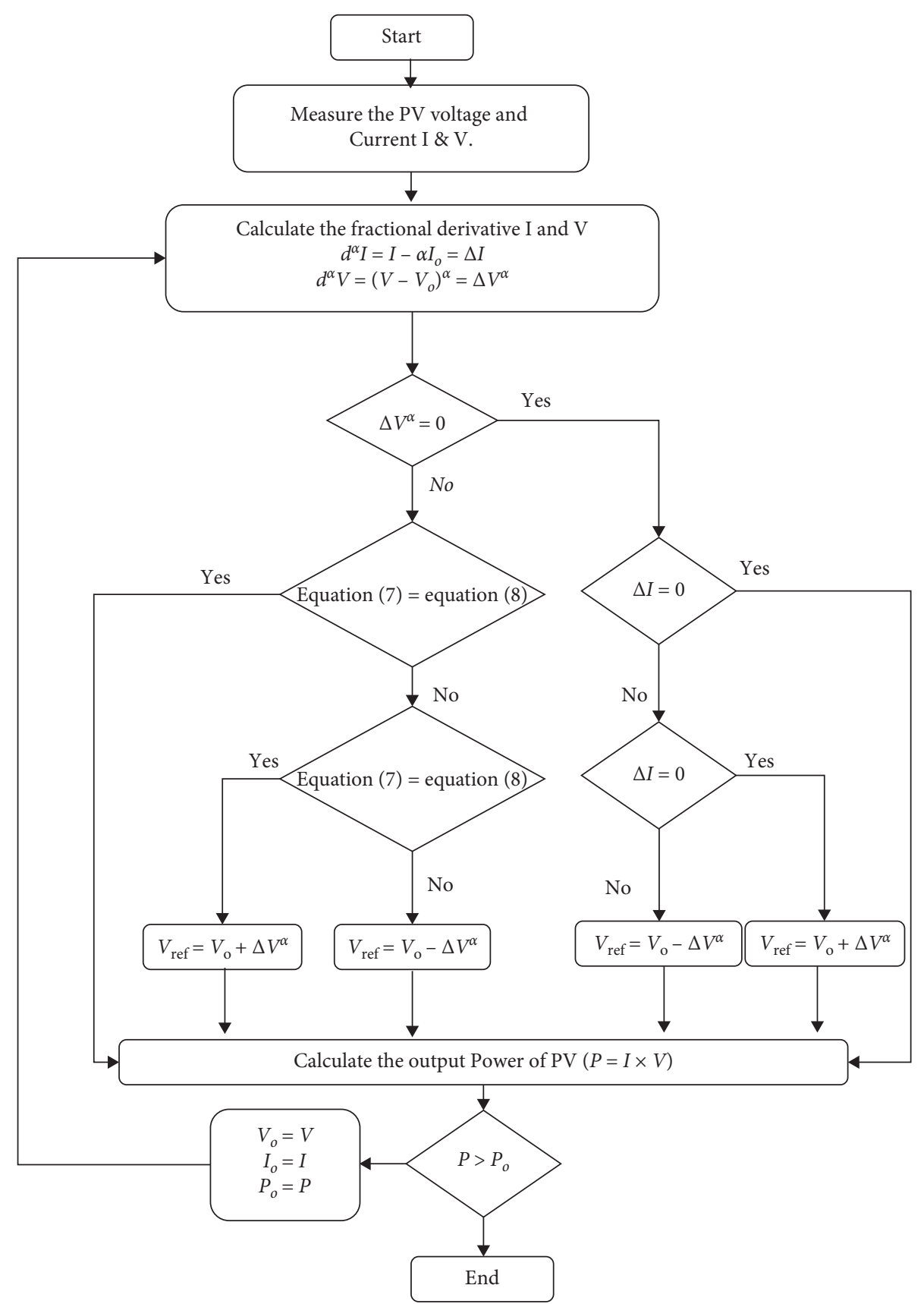

FIgURE 6: Fractional order INC MPPT flowchart.

In Algorithm 2, $\tau_{i j}(t)$ represents the intensity of trail on connection $(i, j)$ at time $t, L(\mathrm{ant})$ is the cost function result at each ant, and $\lambda$ is pheromone decay coefficient between time $(t$ and $t+1)$ (i.e., $0<\lambda<1$ ). Evaporation occurs in real trails, but it is too slow to play an important role. For continuous improvements it allows the search routine to forget errors and poor quality solution in favor of better ones.

4.3. AntLion Optimizer Optimization (ALO). The primary motive of ALO is the running behavior of larvae of antlions.
ALO is suggested based on the Emary and Zawbaa [24] mathematical model. The ALO algorithm simulates the interaction between the traps. The ants must move across the search area in order to model such interactions, and the antlions are permitted to chase and fit the traps. Given that ants move randomly to find food in actual life, a random walk algorithm is selected as shown in Heidari et al. [25] to model the ants' motion.

In Algorithm 3, $I$ is a ratio, $c^{t}$ is the minimum of all variables at $t$ th iteration, and $d^{t}$ indicates the vector including the maximum of all variables at $t$ th iteration. $I=10^{w}(T / t)$, where $t$ is the current iteration, $T$ is the 
Result: MPPT parameter to achieve MPP

Initialize the PSO parameters $\left(N, C_{1}, C_{2}, W_{\min }, W_{\max }, V_{\max }\right)$

while the termination criteria not achieved (MPP) do

For (each Particle $i$ )

Simulate and calculate the MPP and the cost function. if CostFunction $(i)<$ Objective(MPP)

then

The Best Cost $(i)=$ Cost Function $(i)$

else The Best Solution $(i)=$ The particle $(i)$

The Best Cost $(i)=$ The Best Cost $(i-1)$ end The Best Solution $(i)=$ The Best Solution $(i-1)$

(a) Update the velocity $(V): V_{i}^{t+1}=V_{i}^{t}+C_{1} r_{1}\left(P_{i}-X_{i}^{t}\right)+C_{2} r_{2}\left(P_{g}-X_{i}^{t}\right)$

where $V_{i}^{t}$ is inertia, $C_{1} r_{1}\left(P_{i}-X_{i}^{t}\right)$ is cognitive component and $C_{2} r_{2}\left(P_{g}-X_{i}^{t}\right)$ is social component end

(b) Update the position of particles: $X_{i}^{t+1}=X_{i}^{t+1}+V_{i}^{t}$

Algorithm 1: PSO-MPPT.

Result: MPPT parameter to achieve MPP

Initialize the ACO parameters

while the termination criteria not achieved (MPP) do

For (each ant $i$ )

Simulate and calculate the MPP and the cost Function.

if CostFunction $(i)<$ Objective (MPP) then

The Best Cost $(i)=$ Cost Function $(i)$

else

The Best Solution $(i)=$ The particle $(i)$

The Best Cost $(i)=$ The Best Cost $(i-1)$

The Best Solution $(i)=$ The Best Solution $(i-1)$

end

(a) Update pheromone for each ant: $\tau_{i j}(t+1), \Delta \tau_{i j}(t)=\sum_{\text {ant }=1}^{\text {ants }} \Delta \tau_{i j}^{\text {ant }}(t)$

(i) Calculate the solution $\Delta \tau_{i j}^{\text {ant }}(t)=\left\{\begin{array}{l}\left(1 / L_{\text {best }}\right) \longrightarrow \text { if ant }(t) \text { travels on edge }(i, j) \\ 0 \longrightarrow \text { otherwise }\end{array}\right.$ end

(b) Apply evaporation and globally update the ants position, according to the optimum solutions calculated earlier

Algorithm 2: ACO-MPPT.

maximum number of iterations, and $w$ is a constant defined based on the current iteration. $X(t)$ is ant' movement, cumsum calculates the cumulative sum, $n$ is the maximum number of iteration, $t$ shows the step of random walk, and $r(t)$ is a stochastic function. Also, $a_{i}$ is the minimum of random walk and $b_{i}$ is the maximum of random walk in $i$ th variable. $R_{\mathrm{A}}^{t}$ is the random walk around the antlion selected by the roulette wheel at $t$ th iteration and $R_{\mathrm{E}}^{t}$ is the random walk around the elite at $t$ th iteration. The pseudo code of ALO for MPPT developed as mentioned in Algorithm 3.

\section{Modeling and Simulation Results}

The proposed system has been modeled and simulated using MATLAB and Simscape software environments in order to study the system behavior and MPPT performance with different metaheuristic optimization algorithms. The block diagram describing the total PV system with MPPT and optimizer is shown in Figure 7, where the MPPT algorithm is changed between conventional INC methods and FO-INC (fixed and variable step). The MPPT is optimized by one of the metaheuristic techniques (PSO, ACO, and ALO).

The operation sequence of PV with MPPT and optimization process is a closed loop as shown in Figure 8, and it starts with measuring the irradiance $(G)$ and temperature (T) applied to the PV system to get the reference maximum power point from $\mathrm{PV}$ characteristics curves $\left(P_{\mathrm{MPP}}\right)$. A closed loop of PV with MPPT and Buck-Boost converter is running in Simscape environment for two seconds to measure the PV output power. The mean squared-error (MSE) between the MPP $\left(P_{\mathrm{MPP}}\right)$ and output power of the PV system $\left(P_{\mathrm{PV}}\right)$ is the cost function of the metaheuristic optimizer calculated 
Result: MPPT parameter to achieve MPP

Initialize the first population of ants and antlions randomly

while the termination criteria not achieved (MPP) do

For (each antlion $(i))$

Select an antlion using Roulette wheel algorithm [16].

Simulate and calculate the MPP and the cost Function. if CostFunction $(i)<\operatorname{Objective(MPP)}$

then

The Best Cost $(i)=$ Cost Function $(i)$

The elite $(i)=$ The The Best Solution $(i)$

else

The Best Cost $(i)=$ The Best Cost $(i-1)$

The elite $(i)=$ The Best Solution $(i-1)$

end

(a) Update $c$ and $d$ using equations: $C^{t}=\left(C^{t} / I\right)$ and $d^{t}=\left(d^{t} / I\right)$

(b) Create a random walk and normalize it using: $X(t)=\left[0, \ldots, \operatorname{cumsum}\left(2 r\left(t_{n}\right)-1\right)\right]$, where $n=1,2,3, \ldots, n$ and $X_{i}^{t}=\left(\left(X_{i}^{t}-a_{i}\right) \times\left(d_{i}-c_{i}^{t}\right) /\left(d_{i}^{t}-a_{i}\right)\right)+c_{i}$

(c) Update the position of antlions using ant ${ }_{i}^{t}=\left(R_{\mathrm{A}}^{t}+R_{\mathrm{E}}^{t}\right) / 2$

(d) Calculate the fitness of all ants according to the optimum solutions calculated earlier end

Algorithm 3: ALO-MPPT.

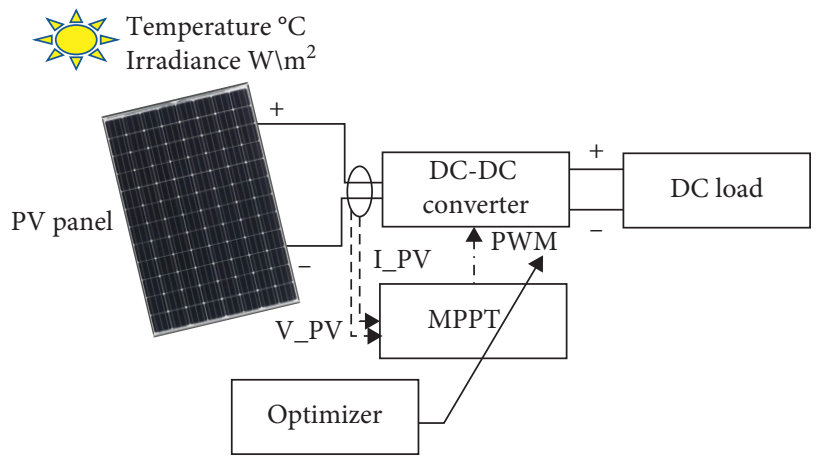

Figure 7: The proposed PV system with metaheuristic optimization.

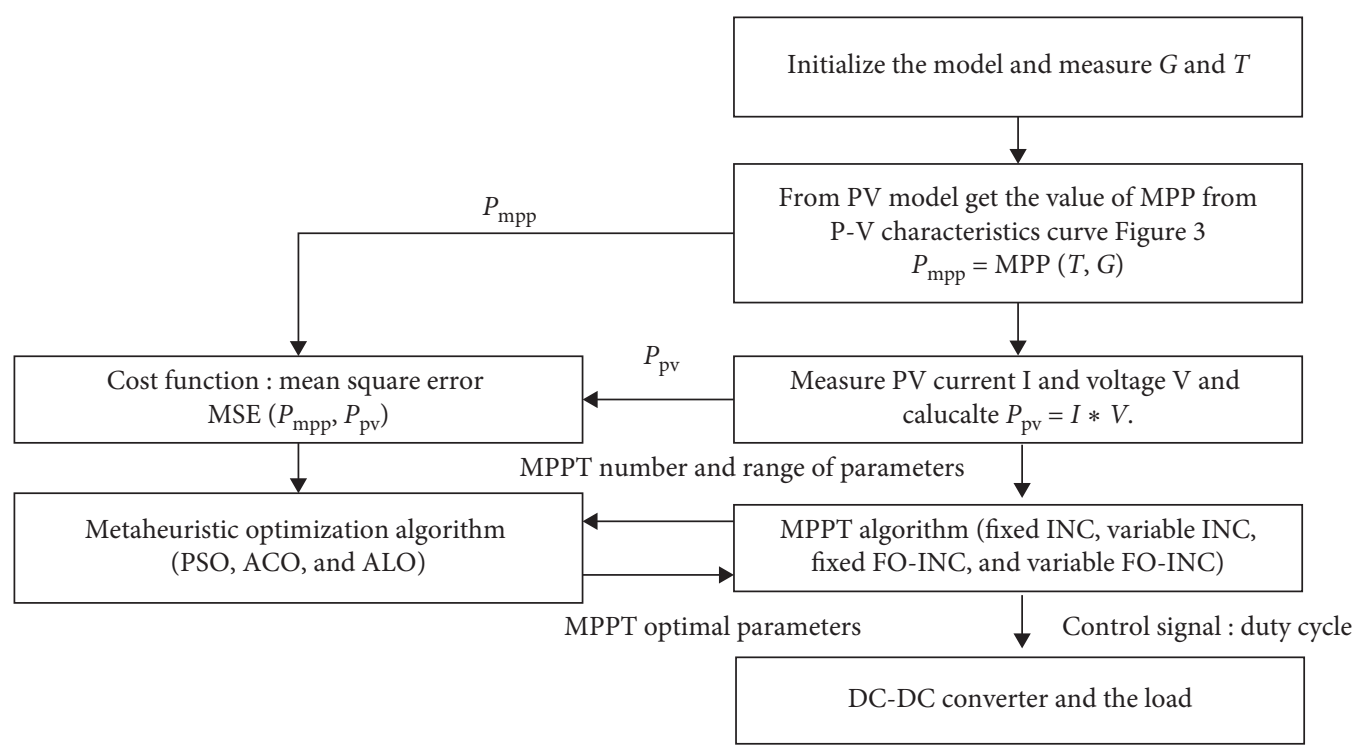

FIgURE 8: The proposed system implementation flowchart. 
TABLE 3: Comparative results between MPPT algorithms at $800 \mathrm{~W} / \mathrm{m}^{2}$.

\begin{tabular}{|c|c|c|c|c|c|c|c|c|}
\hline \multicolumn{9}{|c|}{ Climatic condition } \\
\hline \multirow[b]{2}{*}{ MPPT } & \multicolumn{4}{|c|}{$800 \mathrm{~W} / \mathrm{m}^{2}$ and $25^{\circ} \mathrm{C}$} & \multicolumn{4}{|c|}{$800 \mathrm{~W} / \mathrm{m}^{2}$ and $35^{\circ} \mathrm{C}$} \\
\hline & $\begin{array}{l}\text { Max power } \\
\text { (Watt) }\end{array}$ & $\begin{array}{l}\text { MPP } \\
\text { steps }\end{array}$ & $\begin{array}{l}\text { Oscillation avg. } \\
\text { (Watt) }\end{array}$ & $\begin{array}{l}\text { No. of } \\
\text { iterations }\end{array}$ & $\begin{array}{l}\text { Max power } \\
\text { (Watt) }\end{array}$ & $\begin{array}{l}\text { MPP } \\
\text { steps }\end{array}$ & $\begin{array}{l}\text { Oscillation avg. } \\
\text { (Watt) }\end{array}$ & $\begin{array}{l}\text { No. of } \\
\text { iterations }\end{array}$ \\
\hline Fixed-step INC & 321.84 & 137 & 5.87 & - & 319.73 & 131 & 4.92 & - \\
\hline Variable-step INC & 324.63 & 125 & 4.89 & - & 319.90 & 127 & 4.17 & - \\
\hline $\begin{array}{l}\text { FO-INC fixed } \\
\text { step + PSO }\end{array}$ & 420.28 & 121 & 4.28 & 100 & 400.01 & 127 & 4.34 & 100 \\
\hline $\begin{array}{l}\text { FO-INC fixed } \\
\text { step + ACO }\end{array}$ & 470.62 & 115 & 4.067 & 100 & 462.24 & 121 & 3.089 & 100 \\
\hline $\begin{array}{l}\text { FO-INC fixed } \\
\text { step + ALO }\end{array}$ & 487.22 & 118 & 3.067 & 100 & 474.24 & 125 & 3.089 & 100 \\
\hline $\begin{array}{l}\text { FO-INC variable } \\
\text { step + PSO }\end{array}$ & 490.28 & 128 & 3.28 & 100 & 480.01 & 132 & 3.34 & 100 \\
\hline $\begin{array}{l}\text { FO-INC variable } \\
\text { step + ACO }\end{array}$ & 510.62 & 115 & 3.067 & 100 & 490.24 & 121 & 3.089 & 100 \\
\hline $\begin{array}{l}\text { FO-INC variable } \\
\text { step + ALO }\end{array}$ & 515.52 & 120 & 3.269 & 100 & 510.26 & 127 & 3.802 & 100 \\
\hline
\end{tabular}

TABLE 4: Comparative results between MPPT algorithms at $1000 \mathrm{~W} / \mathrm{m}^{2}$

\begin{tabular}{|c|c|c|c|c|c|c|c|c|}
\hline \multicolumn{9}{|c|}{ Climatic condition } \\
\hline \multirow[b]{2}{*}{ MPPT } & \multicolumn{4}{|c|}{$1000 \mathrm{~W} / \mathrm{m}^{2}$ and $25^{\circ} \mathrm{C}$} & \multicolumn{4}{|c|}{$1000 \mathrm{~W} / \mathrm{m}^{2}$ and $35^{\circ} \mathrm{C}$} \\
\hline & $\begin{array}{l}\text { Max power } \\
\text { (Watt) }\end{array}$ & $\begin{array}{l}\text { MPP } \\
\text { steps }\end{array}$ & $\begin{array}{l}\text { Oscillation avg. } \\
\text { (Watt) }\end{array}$ & $\begin{array}{l}\text { No. of } \\
\text { iterations }\end{array}$ & $\begin{array}{l}\text { Max power } \\
\text { (Watt) }\end{array}$ & $\begin{array}{l}\text { MPP } \\
\text { steps }\end{array}$ & $\begin{array}{l}\text { Oscillation avg. } \\
\text { (Watt) }\end{array}$ & $\begin{array}{l}\text { No. of } \\
\text { iterations }\end{array}$ \\
\hline Fixed-step INC & 428.84 & 145 & 4.87 & - & 419.73 & 153 & 5.92 & - \\
\hline Variable-step INC & 420.73 & 155 & 5.87 & - & 419.90 & 139 & 5.17 & - \\
\hline $\begin{array}{l}\text { FO-INC fixed } \\
\text { step + PSO }\end{array}$ & 436.88 & 120 & 4.88 & 100 & 410.51 & 121 & 4.84 & 100 \\
\hline $\begin{array}{l}\text { FO-INC fixed } \\
\text { step + ACO }\end{array}$ & 650.82 & 101 & 2.067 & 100 & 632.24 & 112 & 2.089 & 100 \\
\hline $\begin{array}{l}\text { FO-INC fixed } \\
\text { step + ALO }\end{array}$ & 667.32 & 118 & 3.87 & 100 & 664.24 & 120 & 3.889 & 100 \\
\hline $\begin{array}{l}\text { FO-INC variable } \\
\text { step + PSO }\end{array}$ & 590.28 & 86 & 2.28 & 100 & 580.23 & 92 & 2.34 & 100 \\
\hline $\begin{array}{l}\text { FO-INC variable } \\
\text { step + ACO }\end{array}$ & 720.62 & 65 & 2.067 & 100 & 705.24 & 71 & 2.079 & 100 \\
\hline $\begin{array}{l}\text { FO-INC variable } \\
\text { step + ALO }\end{array}$ & 725.32 & 80 & 2.369 & 100 & 710.63 & 96 & 2.802 & 100 \\
\hline
\end{tabular}

in MATLAB environment to get the optimal MPPT parameters. The optimal parameters are applied to the chosen MPPT technique in Simscape. Performance index is calculated in MATLAB through a dynamical data exchange between MATLAB and Simscape.

The proposed MPPT contribution is generated by measuring the output energy of the PV system under different solar irradiances. Simulation was conducted when solar radiation and cell temperature change with a transient method of approximately $2 \mathrm{sec}$ with $0.01 \mathrm{sec}$ sampling. The characteristics of the PV array will be altered when the natural radiation and cell temperature alter, which causes the I-V curves of the PV array to change. In addition, the particular irradiance ranges from 400 to $1000 \mathrm{~W} / \mathrm{m}^{2}$ and the cell temperature ranges from $20^{\circ} \mathrm{C}$ to $40^{\circ} \mathrm{C}$ which makes it more realistic as shown in Tables 3 and 4 .
Figure 9 shows the I-V and P-V curves of fixed-step INC under different temperature and radiation with small step which in return gives it better results and less oscillation; however, it takes more time to get maximum power. The variable-step INC curves, shown in Figure 10, give better results than the fixed INC. However, in variable-step INC, improper selection of the initial step size may require large number of steps to reach the MPP. Also, improper selection of the scaling factor may lead to oscillations.

The objective of PSO, ACO, and ALO is to select the best value of $\alpha$ for the fixed-step FO-INC and the best values of $\alpha$ and $S$ for variable step to get the maximum PV power. Fixedstep FO-INC MPPT results optimized by PSO, ACO, and ALO are shown in Figure 11. Fixed-step FO-INC-PSO gives better results than conventional INC methods, less number of MPPT steps to maximum power value, and less oscillation, yet PSO optimization needs more iterations to get the 


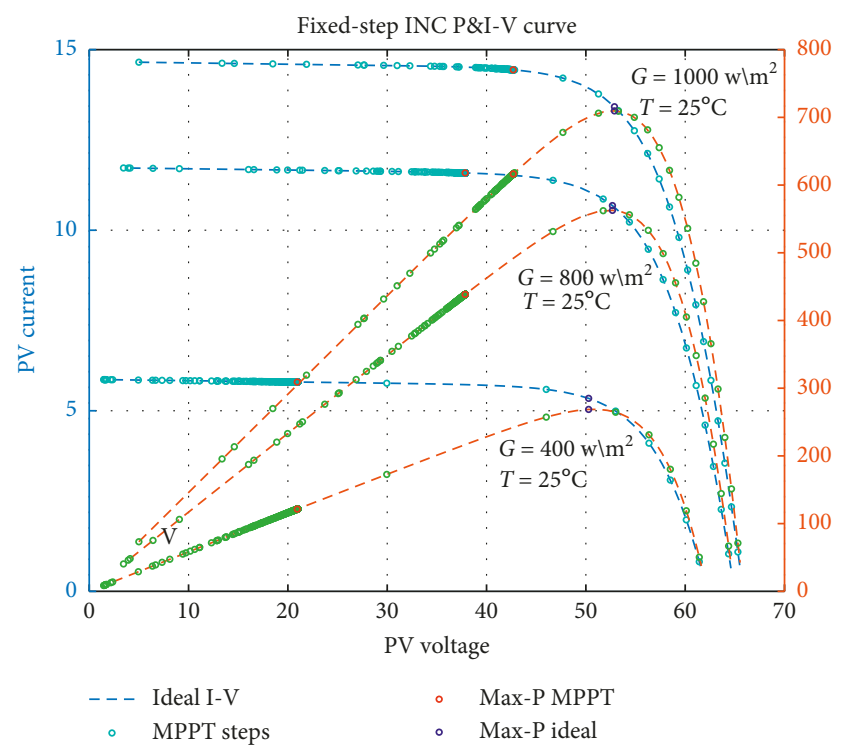

Figure 9: Fixed-step INC I-V and P-V curves.

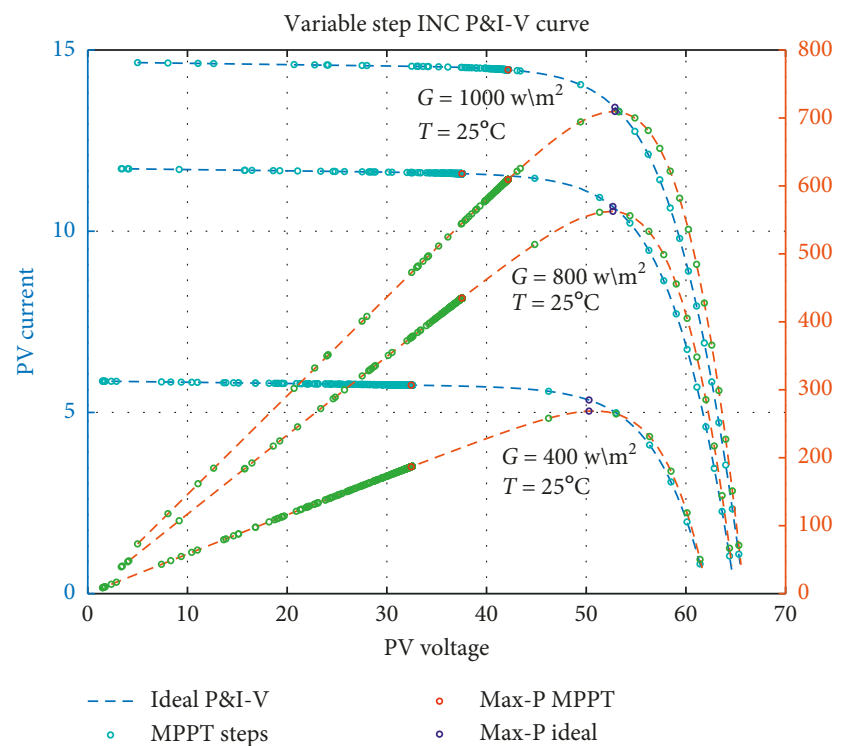

Figure 10: Variable-step INC I-V and P-V curves.

optimal MPPT parameter. Fixed-step FO-INC-ACO gives less number of MPPT steps than PSO and ALO, however, not the optimum parameter that can be obtained by ALO with fewer number of MPPT steps. The output power and voltage of the PV system generated using the optimization of fixed-step FO-INC-ACO gives less oscillation yet not as much maximum power as given by ALO as shown in Figure 12. Variable-step FO-INC gives better results than conventional INC and fixed-step FO-INC methods, less number of MPPT steps to maximum power value, and less oscillation. PSO needs more number of iterations than ACO and ALO to get the optimal MPPT parameters. ALO gives the optimum parameters for the maximum power with larger number of MPPT steps and vice-versa with ACO as shown in Figures 13 and 14.
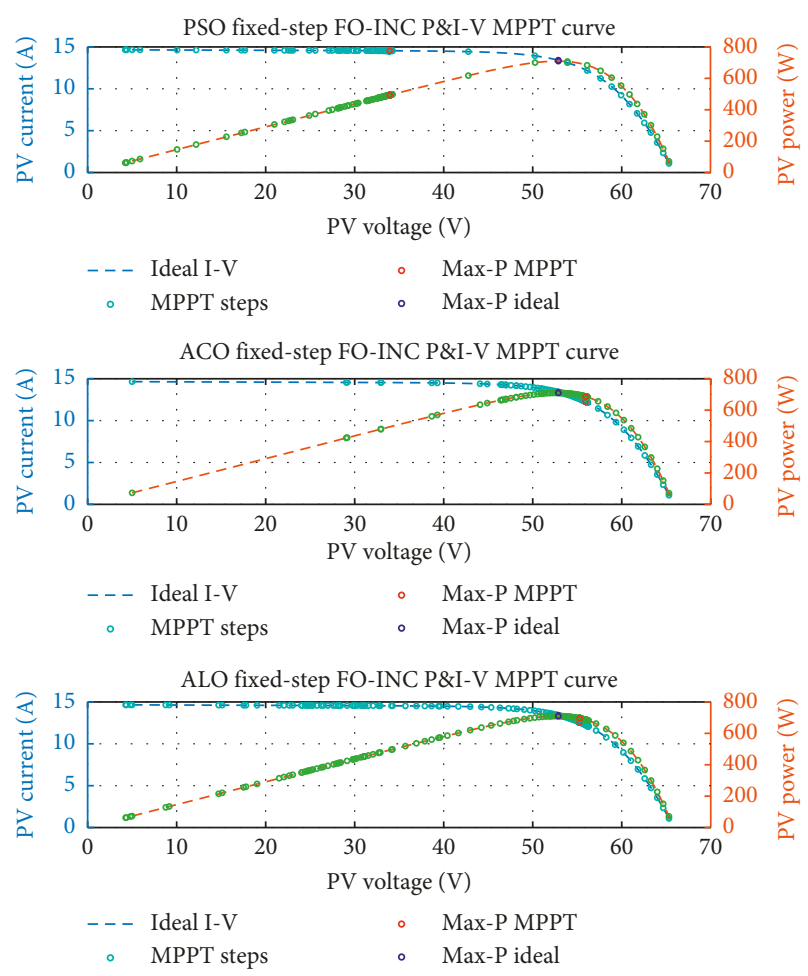

FIGURe 11: Optimization of fixed-step FO-INC I-V and P-V curves.
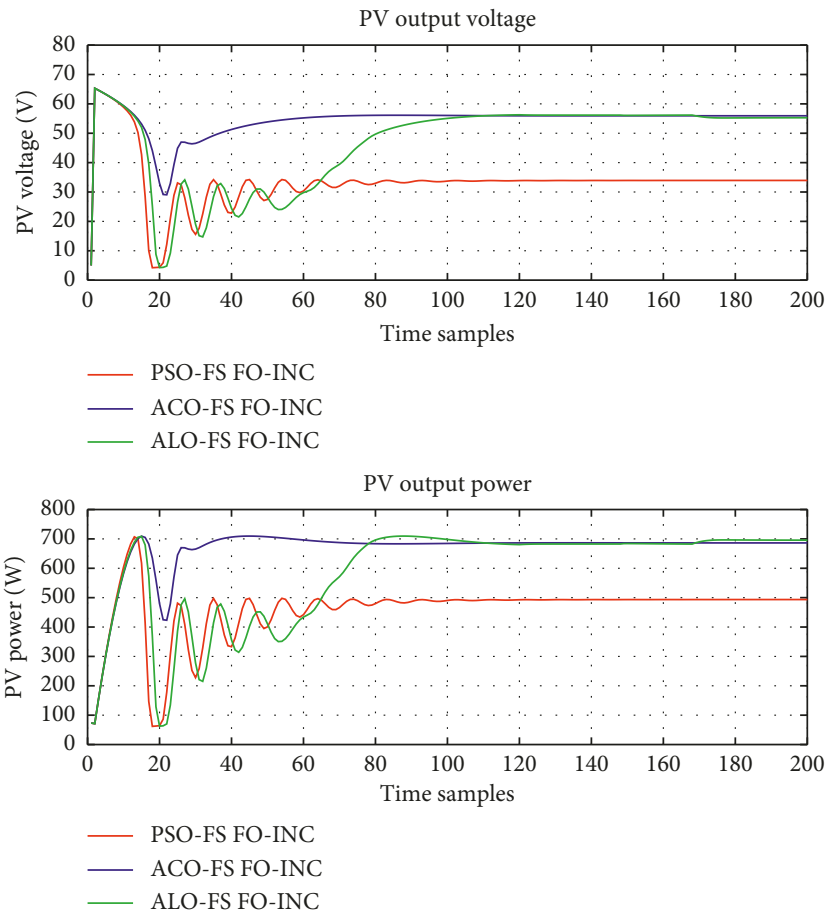

FIGURE 12: Optimization of fixed FO-INC output response.

The MPPT performance $\eta$ can be monitored as in equation (10) for all the abovementioned MPPT techniques. Irradiance, temperature, power, and maximum power time waveform of the system using the proposed MPPT methods have been used 

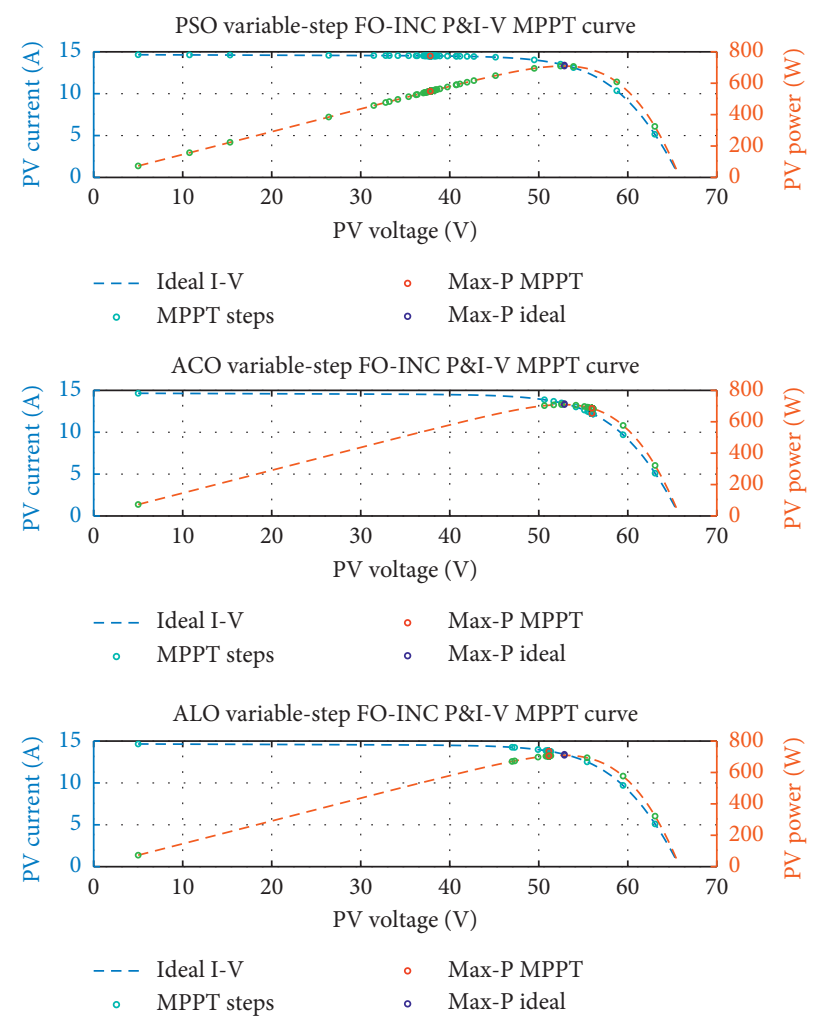

Figure 13: Optimization of variable-step FO-INC I-V and P-V curves.

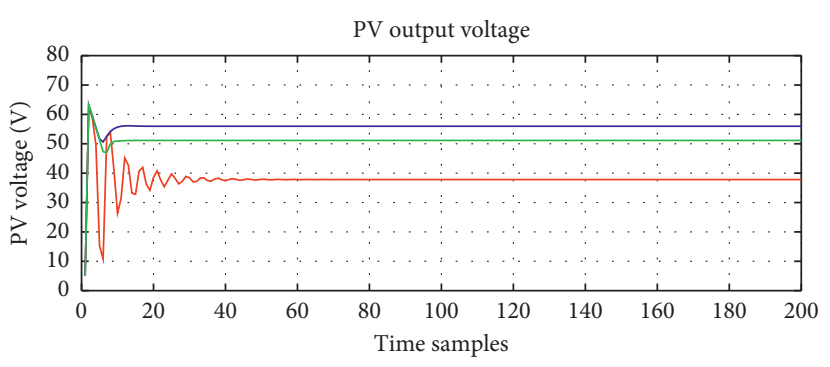

- PSO-VS FO-INC

- ACO-VS FO-INC

- ALO-VS FO-INC

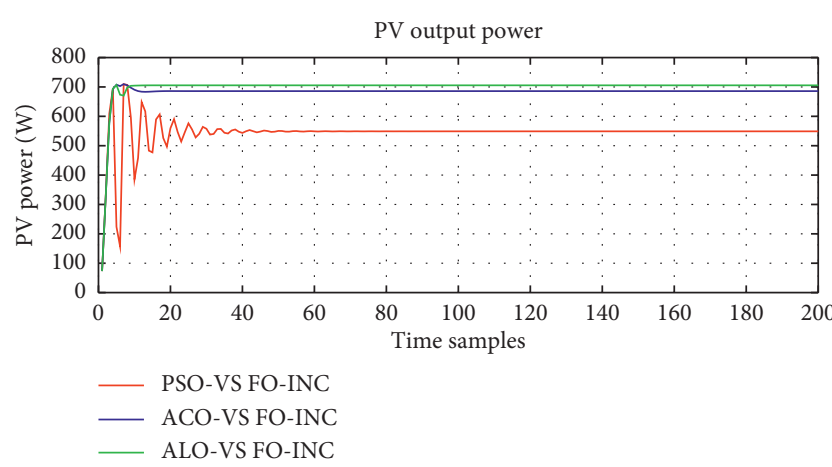

FIgURE 14: Optimization of variable FO-INC output response.

to get $\eta$. The irradiance and temperature variation mean that output power follows the highest maximum power profile very closely, and the higher performance is obtained in case of variable-step FO-INC with ALO (98.1) as noted from Table 5:
TABLE 5: MPPT algorithms efficiency.

\begin{tabular}{lc}
\hline MPPT method & Efficiency $(\eta)$ \\
\hline Fixed-step INC & 75.9 \\
Variable-step INC & 82.1 \\
Fixed-step FO-INC + PSO & 90.2 \\
Fixed-step FO-INC + ACO & 92.3 \\
Fixed-step FO-INC + ALO & 93.2 \\
Variable-step FO-INC + PSO & 94.7 \\
Variable-step FO-INC + ACO & 97.5 \\
Variable-step FO-INC + ALO & 98.1 \\
\hline & \\
$\qquad$ & $\int P_{\mathrm{PV}}(t) \mathrm{d} t$ \\
$P_{\mathrm{MPP}}$. &
\end{tabular}

\section{Conclusion and Future Work}

The output power of the PV system will be changed by irradiance and temperature according to the simulation results of the system with different climatic conditions as illustrated in Tables 3 and 4 . The proposed incremental fractional order FO-INC demonstrates better results than traditional INC under environmental changing processes and improves the efficiency of MPPT as FO-INC is able to provide a dynamical mathematical model for describing the nonlinear and fractional properties. The incremental change in the fractional order as a dynamic variable is used to adjust the MPPT service cycle. Using metaheuristic optimization enhances the performance of FO-INC and 
provides another dynamical variable to the MPPT control. Compared to ACO and ALO, the PSO uses less number of variables and shorter calculation time for the same number of iterations. However, sometimes it cannot achieve the optimal solution. The ALO uses larger number of variables and takes the longest calculation time, yet it gives more optimal solution compared to ACO and PSO. This work could be extended by changing the resistance using another dynamical load, e.g., DC motor, or by applying different optimization techniques on the FO-INC.

\section{Data Availability}

No data were used to support this study.

\section{Conflicts of Interest}

The authors declare that they have no conflicts of interest.

\section{Acknowledgments}

The authors would like to thank Prince Sultan University, Riyadh, Saudi Arabia for supporting and funding this work. Special acknowledgment to Robotics and Internet-of-Things Lab (RIOTU) at Prince Sultan University, Riyadh, SA.

\section{References}

[1] M. A. Jusoh, M. F. Naim Tajuddin, S. M. Ayob, and M. A. Roslan, "Maximum power point tracking charge controller for standalone PV system," TELKOMNIKA (Telecommunication Computing Electronics and Control), vol. 16, no. 4, pp. 1413-1426, 2018

[2] P. G. Bueno, F. J. Ruiz-Rodriguez, and J. C. Hernández, "Stability assessment for transmission systems with large utility-scale photovoltaic units," IET Renewable Power Generation, vol. 10, no. 5, pp. 584-597, 2016.

[3] B.-R. Peng, K.-C. Ho, and Y.-H. Liu, "A novel and fast mppt method suitable for both fast changing and partially shaded conditions," IEEE Transactions on Industrial Electronics, vol. 65, no. 4, pp. 3240-3251, 2018.

[4] H. Bahri and A. Harrag, "Variable step size P\&O MPPT controller to improve static and dynamic PV system performances," Journal of Advanced Engineering and Computation, vol. 2, no. 2, pp. 86-93, 2018.

[5] S. Motahhir, A. El Ghzizal, S. Sebti, and A. Derouich, "Modeling of photovoltaic system with modified incremental conductance algorithm for fast changes of irradiance," International Journal of Photoenergy, vol. 2018, Article ID 3286479, 13 pages, 2018.

[6] M. Seyedmahmoudian, T. Kok Soon, E. Jamei et al., "Maximum power point tracking for photovoltaic systems under partial shading conditions using bat algorithm," Sustainability, vol. 10, no. 5, p. 1347, 2018.

[7] L. Li, H. Wang, X. Chen et al., "High efficiency solar power generation with improved discontinuous pulse width modulation (dpwm) overmodulation algorithms," Energies, vol. 12, no. 9, p. 1765, 2019.

[8] J. Li and H. Wang, "A novel stand-alone PV generation system based on variable step size INC MPPT and SVPWM control," in Proceedings of the 2009 IEEE 6th International Power Electronics and Motion Control Conference, pp. 21552160, IEEE, Wuhan, China, May 2009.
[9] C. Milici, G. Drăgănescu, and J. T. Machado, Introduction to Fractional Differential Equations, vol. 25, Springer, Basel, Switzerland, 2019.

[10] K.-N. Yu, C.-K. Liao, and H.-T. Yau, "A new fractional-order based intelligent maximum power point tracking control algorithm for photovoltaic power systems," International Journal of Photoenergy, vol. 2015, Article ID 493452, 8 pages, 2015.

[11] M. A. Ebrahim and R. Mohamed, "Comparative study and simulation of different maximum power point tracking (MPPT) techniques using fractional control \& grey wolf optimizer for grid connected pv system with battery," in Electric Power Conversion, IntechOpen, London, UK, 2019.

[12] M. Dorigo and T. Stützle, "Ant colony optimization: overview and recent advances," in Handbook of Metaheuristics, pp. 311-351, Springer, 2019.

[13] J. Kumar, K. V. Azar Ahmad Taher, and R. K. P. Singh, "Design of fractional order fuzzy sliding mode controller for nonlinear complex systems," in Mathematical Techniques of Fractional Order Systems, pp. 249-282, Elsevier, 2018 a.

[14] Y. Sun and Y. Yihan, "Non-inverting buck-boost converter control," US Patent App. 15/729,366, 2018.

[15] A. Mohapatra, Optimized parameter estimation, array configuration and MPPT control of standalone photovoltaic system, Ph.D. thesis, National Institute of Technology, Rourkela, India, 2018.

[16] K. Sundareswaran, V. Vigneshkumar, P. Sankar, S. P. Simon, P. S. R. Nayak, and S. Palani, "Development of an improved $\mathrm{P} \& \mathrm{O}$ algorithm assisted through a colony of foraging ants for mppt in PV system," IEEE Transactions on Industrial Informatics, vol. 12, no. 1, pp. 187-200, 2015.

[17] S. Duman, N. Yorukeren, and I. H. Altas, "A novel MPPT algorithm based on optimized artificial neural network by using FPSOGSA for standalone photovoltaic energy systems," Neural Computing and Applications, vol. 29, no. 1, pp. 257278, 2018.

[18] R. Sahu and B. Shaw, "Design of solar system by implementing alo optimized pid based mppt controller," Trends in Renewable Energy, vol. 4, no. 3, pp. 44-55, 2018.

[19] B. Oubbati, M. Boutoubat, M. Belkheiri, and A. Rabhi, "Extremum seeking and P\&O control strategies for achieving the maximum power for a PV array," in International Conference in Artificial Intelligence in Renewable Energetic Systems, pp. 233-241, Springer, Cham, Switzerland, 2018.

[20] R. Pradhan, S. Pradhan, and B. B. Pati, "Design and performance evaluation of fractional order PID controller for heat flow system using particle swarm optimization," in Computational Intelligence in Data Mining, pp. 261-271, Springer, Cham, Switzerland, 2019.

[21] N. A. Kamal and A. M. Ibrahim, "Conventional, intelligent, and fractional-order control method for maximum power point tracking of a photovoltaic system: a review," in Fractional Order Systems, pp. 603-671, Elsevier, Amsterdam, Netherlands, 2018.

[22] Y. Michimura, K. Komori, A. Nishizawa et al., "Particle swarm optimization of the sensitivity of a cryogenic gravitational wave detector," Physical Review D, vol. 97, no. 12, p. 122003, 2018.

[23] P. M. Kumar, U. Devi G, G. Manogaran, R. Sundarasekar, N. Chilamkurti, and R. Varatharajan, "Ant colony optimization algorithm with internet of vehicles for intelligent traffic control system," Computer Networks, vol. 144, pp. 154-162, 2018b. 
[24] E. Emary and H. M. Zawbaa, "Feature selection via lèvy antlion optimization," Pattern Analysis and Applications, vol. 22, no. 3, pp. 857-876, 2018.

[25] A. A. Heidari, H. Faris, S. Mirjalili, I. Aljarah, and M. Mafarja, "Ant lion optimizer: theory, literature review, and application in multi-layer perceptron neural networks," in Nature-Inspired Optimizers, pp. 23-46, Springer, Cham, Switzerland, 2020. 


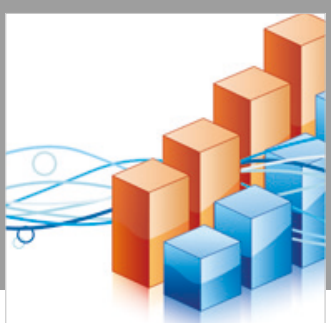

Advances in

Operations Research

\section{-n-m}
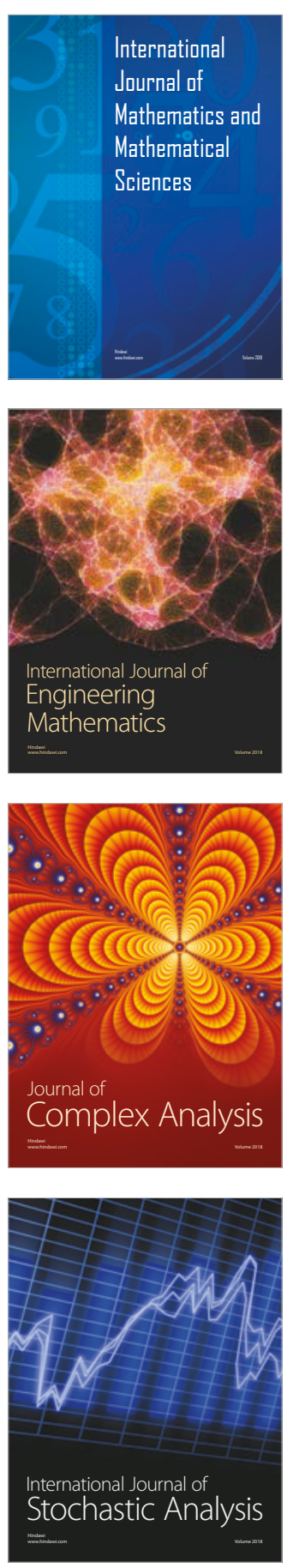
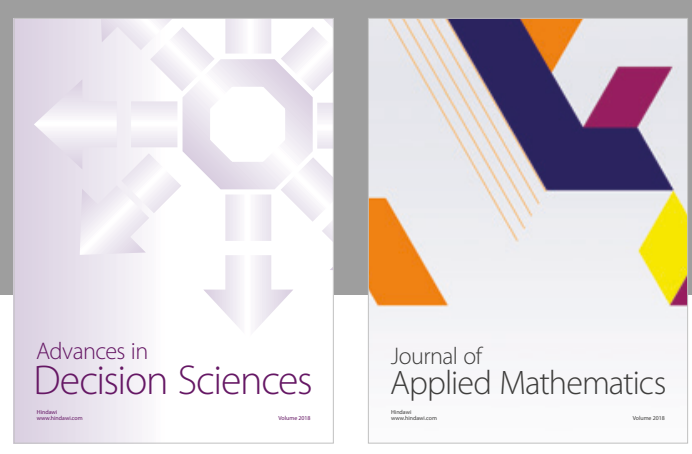

Journal of

Applied Mathematics
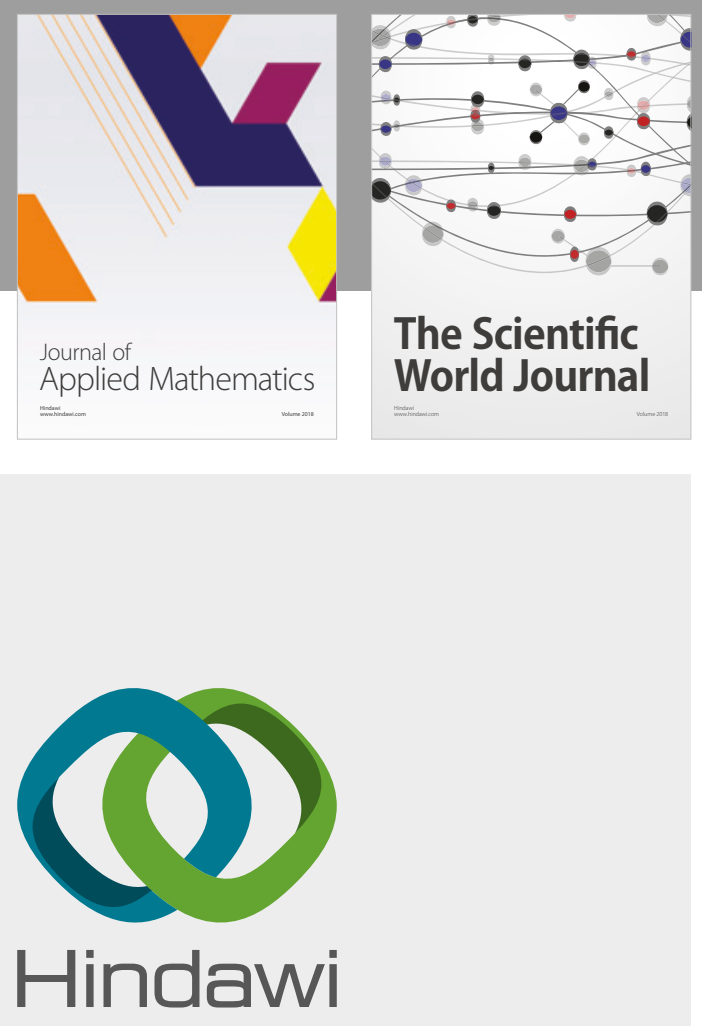

Submit your manuscripts at

www.hindawi.com

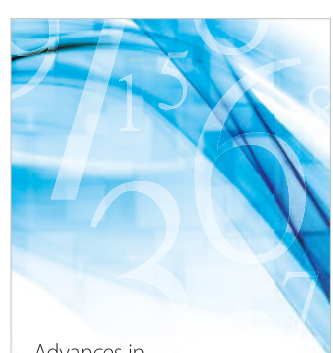

Advances in
Numerical Analysis
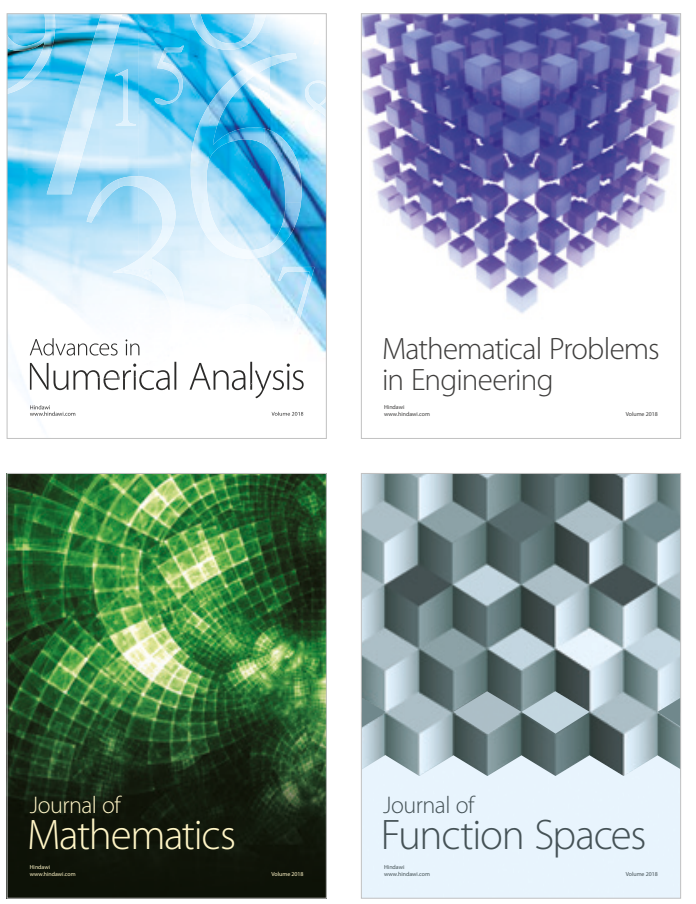

Mathematical Problems in Engineering

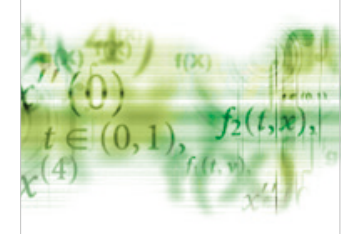

International Journal of

Differential Equations

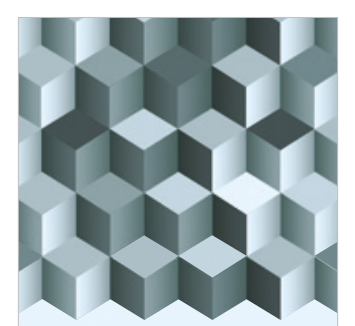

Journal of

Function Spaces
The Scientific

World Journal

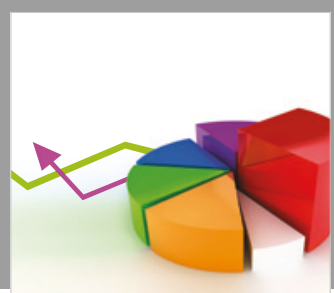

Journal of

Probability and Statistics
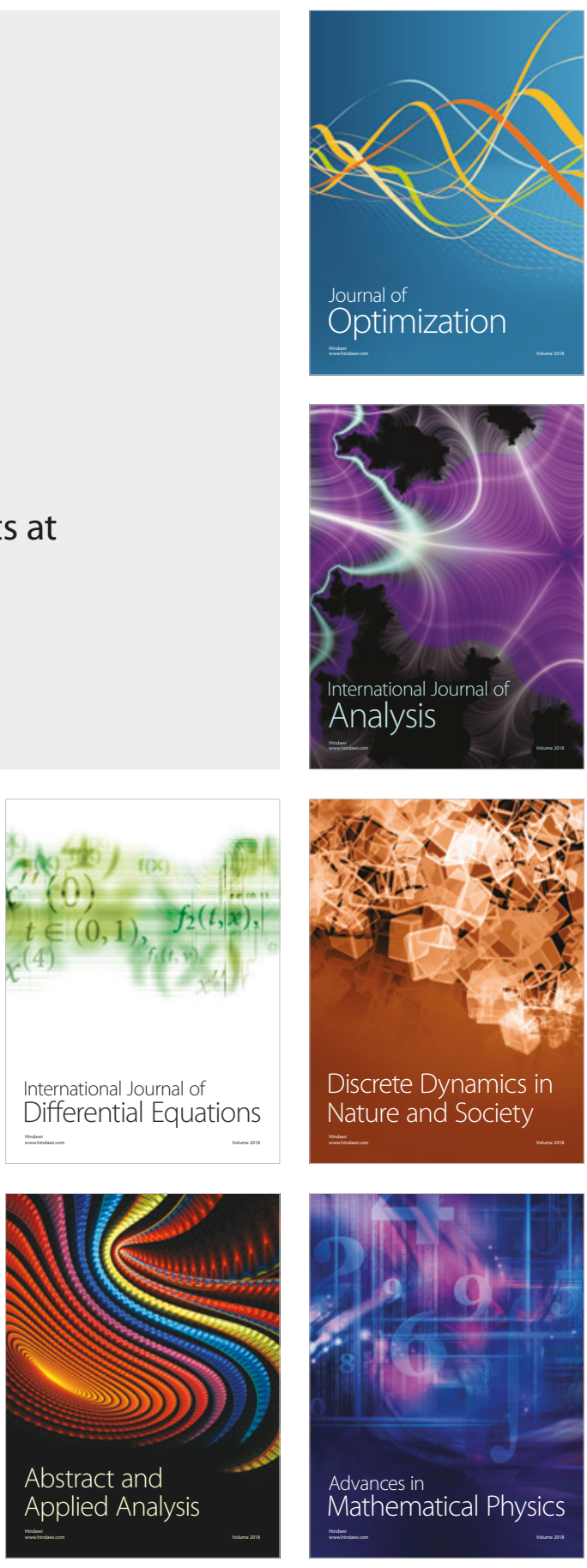